\title{
Structural Response of A Slotted Bridge Pier Under Blast Loading Using Finite Element Analysis
}

\section{Kuldeep R. Patel ${ }^{* 1 a}$, Snehansu Nath*1b}

1 Department of Civil Engineering, Faculty of Technology and Engineering, Parul University of Engineering and Technology(PIET), Vadodara, India.

Article History: Received:11 January 2021; Accepted: 27 February 2021; Published online: 5 April 2021

\begin{abstract}
Bridge pier is a crucial part for the transportation in marine structures. Scouring is a major cause for the failure of the pier. slot among the other countermeasures increases the efficiency of scour reduction and minimizes the failure due to scour.as we provide the slot; the strength of the pier reduces compared to the conventional pier. change in reinforcement pattern in slotted bridge pier changes the behavior of the pier under similar loading conditions. blast occurrence has increased in recent times and rehabilitation of a structure and improvement of strength against explosion is necessary in structure. this paper studies the behavior of slotted bridge pier under blast loading and compares theoretical and analytical aspects for the same. Design criteria for blast load according to NCHRP 12-72 are followed to carry out theoretical load response of the pier under blast loading. Analytically the behavior of pier is checked using coupled eulerian lagrangian approach using ABAQUS software. a detailed eulerian domain and slotted pier with reinforcement is assembled in ABAQUS to analyze the behavior of pier under explosion using TNT of $100 \mathrm{~kg}$ at a scaled distance of $4 \mathrm{ft}$ for the period of 0.02 seconds. this design gave better result in terms of mitigating effects of blast on slotted bridge pier.
\end{abstract}

Keywords: slotted bridge pier; blast loading; CELM analysis; eulerian domain; FEA analysis; ABAQUS.

\section{Introduction}

Bridge is widely used structure as a hydraulics structure in river. As the water passes in the river, the pier becomes an obstruction to the current. The current velocity will reach stagnation point at pier surface and the following water will push down the stagnant water. As an effect of that horse shoe vortex will generate at the base of pier and scouring will occur Figure 1 (W. Zhang et al., 2020). Scouring around the bridge pier is considered to be the major cause of failure of the pier. Provision of slot with the combination of collar proves to be most effective to reduce the scouring around the pier but slot provision reduces the strength of the pier as volume and reinforcement is reduced in the conventional pier(Heidarnejad et al., 2010).

An external blast wave is a phenomenon where surrounding atmosphere gets compressed due to the outward effect of the explosion and gets pushed back(Ibrahim and Nabil, 2019). As the wave propagates, the front portion is known as shock front and it has more pressure compare to the back region of the wave(El-Ghorab, 2013). As the wave propagates it decays with respect to time. As the pressure decays it can get decrease below surrounding pressure and thus creating suction in surrounding region(Ding et al., 2018).

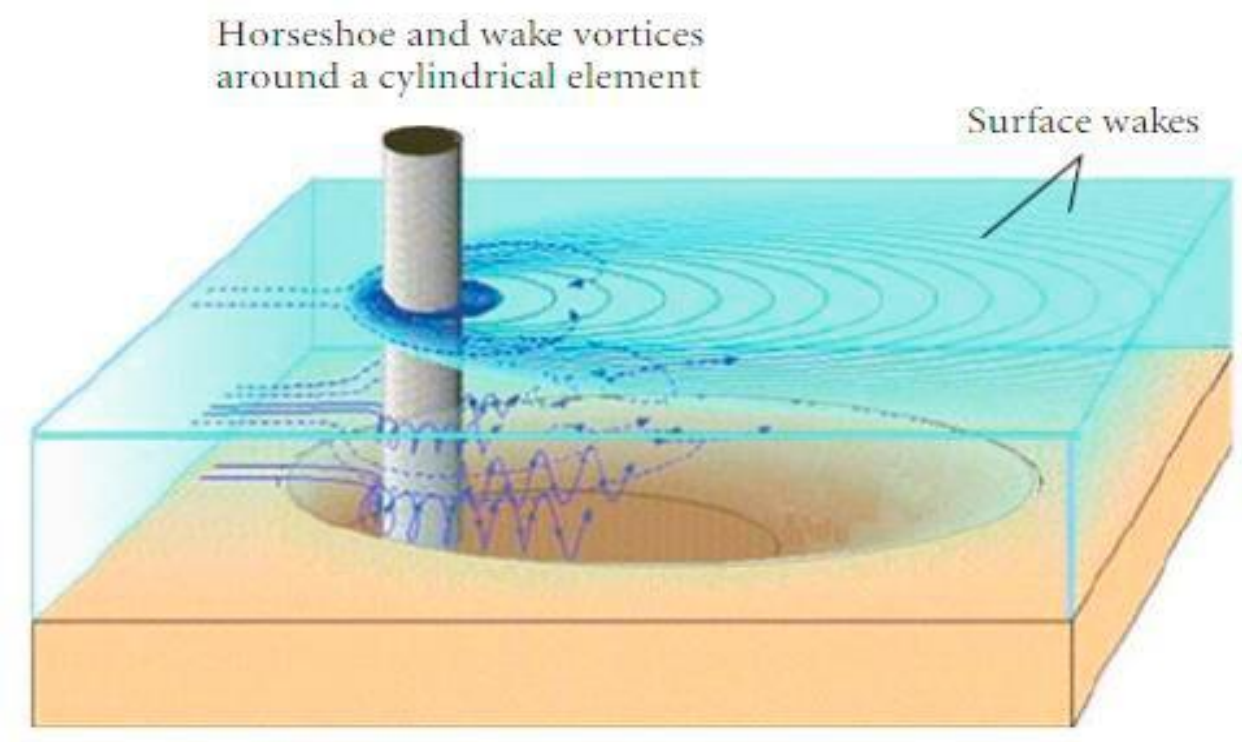

Figure 1 Scouring Around The Bridge Pier Due To Water Current 
An ideal explosion has both the region, one being overpressure also known as positive phase and the other being under pressure also known as negative phase as shown in Figure 2 (Wu et al., 2018).

$\mathrm{t}_{\mathrm{a}}$ is the wave arrival time, $\mathrm{t}_{\mathrm{o}}{ }^{+}$is the duration of the positive phase, $\mathrm{t}_{\mathrm{o}}^{-}$is the total duration of the negative phase, $P^{\square}$ is the peak overpressure, $P_{a}$ is the ambient atmospheric pressure, $P^{\square}$ is the peak under pressure(BlastResistant Highw. Bridg. Des. Detailing Guidel., 2010)(Jin et al., 2020).

In blast explosion scaling is an important parameter to measure the factor of damage induced. Scaling of the explosion as suggested by Hopkinson's Law can be considered. The law states that pressure induced at a distance $\mathrm{R}_{1}$ with explosive weight of $\mathrm{W}_{1}$ will induce same effect as pressure induced at distance $\mathrm{R}_{2}$ with explosive weight as $\mathrm{W}_{2}$ (Sabuwala et al., 2005).

$$
\frac{R_{2}}{R_{1}}=\left(\frac{W_{2}}{W_{1}}\right)^{\frac{1}{3}}=\lambda
$$

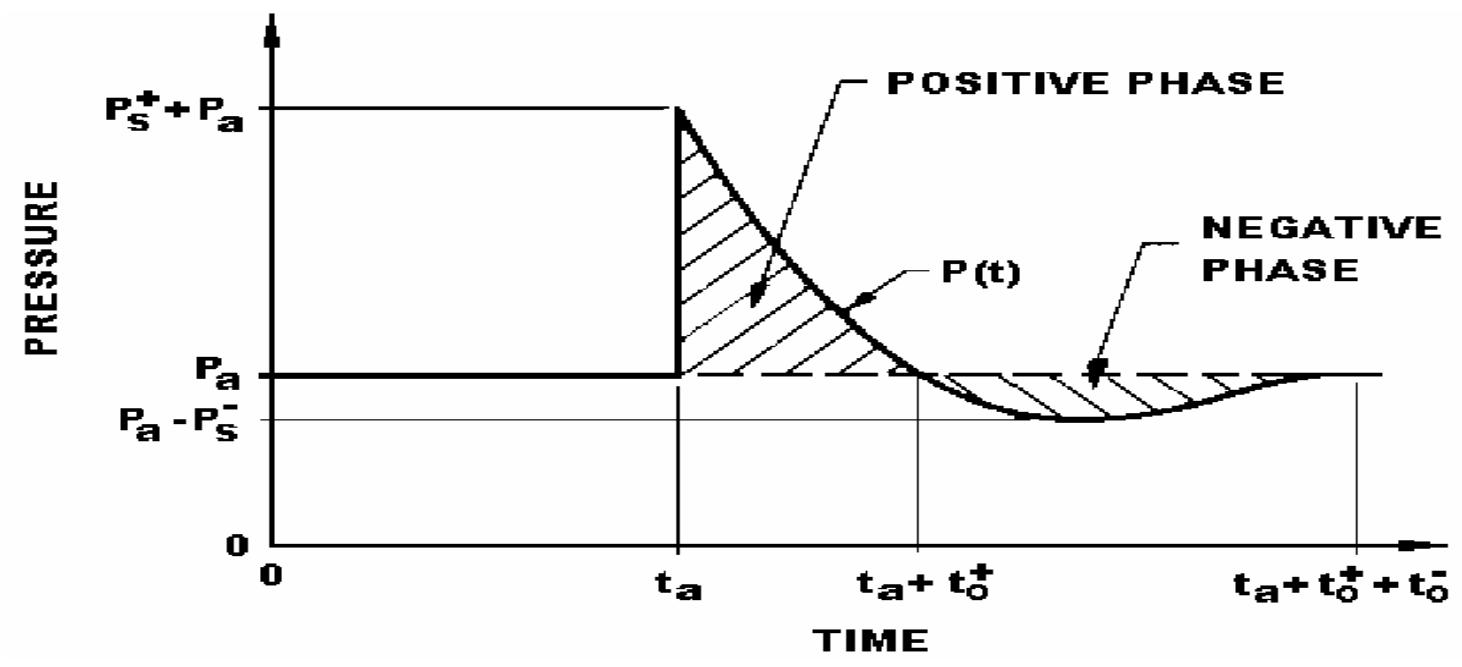

Figure 2 Ideal Blast Wave

The parameter $\lambda$ is referred to as the explosive yield factor. We can also use scaled distance for the explosion as below(C. Zhang et al., 2020).

$$
Z=\frac{R}{\sqrt[3]{W}}
$$

Design guidelines for different structures against blast loading is given by different authorities like US Department of the Army, US Department of Defense, US General Services Administration, American Society of Civil Engineers, National Cooperative Highway Research Program (NCHRP), Federal Highway Administration (FHWA). For this case for bridge pier design we have considered guidelines from National Cooperative Highway Research Program (NCHRP) and considering NCHRP 12-72 which Provides effective methods, structural design, and retrofit guidelines to mitigate the risk of terrorist attacks against critical bridges. We can check the structural integrity and strength against blast loading using this guideline(Miller, 2004).

\section{Theoretical load development and response prediction}

National Cooperative Highway Research Program (NCHRP) provides us with the criteria to design the pier to withstand the blast load in the guidelines under NCHRP 12-72. In our problem case we have considered the predefined data of the pier, reinforcement and material properties for the same(Miller, 2004) (Blast-Resistant Highway Bridges: Design and Detailing Guidelines (2010), 2010).

Pier dimension

Diameter-5 m, cover- $40 \mathrm{~mm}$, length- $10 \mathrm{~m}$

Reinforcement dimension

Longitudinal bar-158-40mm, lateral bars- 30-20mm bars

Standoff distance- $4 \mathrm{ft}$. or $1.33 \mathrm{~m}$, Weight of TNT $-100 \mathrm{Kg}$, Concrete Strength: f'c $=4000$ psi Concrete Unit weight: $\gamma c=150$ pcf, Rebar Modulus of Elasticity: Es $=29000$ ksi Yield Strength: $f y=60 \mathrm{ksi}$ 
From the guidelines we need to calculate certain parameters to design the pier.

$$
Z=\frac{R}{\sqrt[3]{W}}
$$

Here, $\mathrm{Z}=0.26 \mathrm{~m} / \mathrm{kg}^{\frac{1}{3}}$

We can consider this case as category $\mathrm{C}$ loading and design accordingly. Longitudinal Reinforcement Ratio: $\rho \mathrm{L}$ $=\frac{A s}{A g}=1.011 \%$. Volumetric Reinforcement Ratio: $\rho s=\frac{4 A_{v}}{s c c(D-\operatorname{cover})}=1.26 \%$ (C. Zhang et al., 2020)

$$
\rho_{s, \min }=\left\{\begin{array}{c}
0.45\left(\frac{A_{g}}{A_{c}}-1\right) \frac{f^{\prime}{ }_{c}}{f_{y}} \text { if design category }=A \\
0.12 \frac{f^{\prime}{ }_{c}}{f_{y}} \text { if design category }=B \quad \rho_{s, \min }=1.2 \% \\
1.5\left(0.12 \frac{f^{\prime}{ }_{c}}{f_{y}}\right) \text { if design category }=C
\end{array}\right.
$$

Here $\rho$ s is greater than the minimum $\rho$ s required, thus the pier with this dimension will withstand the explosion with this standoff distance and weight of TNT(Moussa et al., 2018).

We also have to calculate pressure intensity and impulse for the same case. We can get these values from the graph shown in Figure 3 by calculating the value of scaling distance Z(Syed et al., 2016).

In our case $\mathrm{Z}=0.26$ thus from the graph we get,

$\mathrm{Po}=9500 \mathrm{MPa}$

Is $=350 \mathrm{MPa}$ m-s and

$\mathrm{To}=3.6 \mathrm{~ms}$ or $0.0036 \mathrm{~s}$

\section{Analytical approach}

Use of ABAQUS software was selected for this study. Due to the use of explosion in analysis the time duration of analysis is of fraction of seconds and thus the element type used in this analysis is 8-noded continuum (brick) elements with reduced integration (C3D8R) for air blast and EC3D8R for coupled eulerian lagrangian domain analysis(Ibrahim and Nabil, 2019). The comparison of blast impact on a pier is observed in two different cases, both for air blast and for partially submerged pier under the effect of blast loading. Critical loading will be found in second analysis as damage done due to blast is much more worst in water than in air. As to create an assembly of partially submerged pier in water, and to create an EoS of a TNT we have to work in eulerian domain in which we can predefine the volumetric fraction and fill the volume with material such as water, air and TNT and analysis the model for that loading(Selvakumaran et al., 2018). To observe the damage in concrete and reinforcement after the failure or blast loading impact we have to provide the material properties for them accordingly. Here in this case material property used for concrete and steel are listed in the Figure 4 below(Hafezolghorani et al., 2017).

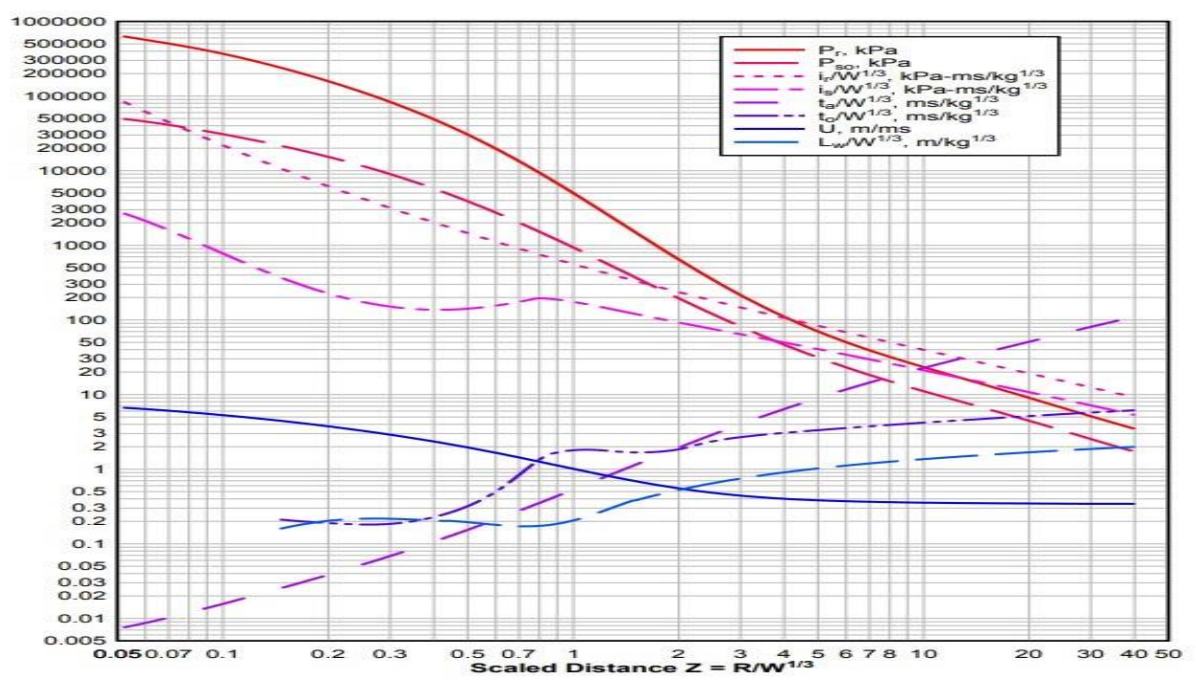

Figure 3 Shock Wave Parameters For Spherical TNT Explosion In Free Air At Sea Level 
The assembly of domain containing water, air, TNT and pier is shown in figure. Eulerian domain can be assigned volume fraction to fill the predefined material in the domain(Jin et al., 2020).

Table 1 part dimensions

\begin{tabular}{|l|l|}
\hline Part & Dimension \\
\hline Pier & $\begin{array}{l}\text { Diameter- 5m, height- } \\
10 \mathrm{~m}\end{array}$ \\
\hline Water domain & $20 \times 20 \times 10 \mathrm{~m}^{3}$ \\
\hline Air domain & $20 \times 20 \times 10 \mathrm{~m}^{3}$ \\
\hline Eulerian domain & $20 \times 20 \times 20 \mathrm{~m}^{3}$ \\
\hline TNT & $0.6 \times 0.6 \times 0.6 \mathrm{~m}^{3}$ \\
\hline
\end{tabular}

In our case we have filled bottom half portion of the domain with water and top half portion of the domain with air. Part dimensions in our case is presented in Table 1.

\begin{tabular}{|c|c|c|c|}
\hline \multirow{2}{*}{$\begin{array}{l}\text { Material's } \\
\text { parameters }\end{array}$} & \multirow[b]{2}{*}{ B30 } & \multicolumn{2}{|c|}{ Plasticity parameters } \\
\hline & & Dilation angle & 31 \\
\hline \multicolumn{2}{|c|}{ Concrete Elasticity } & Eccentricity & 0.1 \\
\hline \multirow[t]{3}{*}{ E (GPa) } & \multirow{3}{*}{$\begin{array}{c}26.6 \\
0.2\end{array}$} & $\mathrm{fbO} / \mathrm{fcO}$ & 1.16 \\
\hline & & $\mathrm{K}$ & 0.67 \\
\hline & & Viscosity parameter & o \\
\hline \multicolumn{2}{|c|}{ Concrete compressive behavior } & \multicolumn{2}{|c|}{ Concrete compression damage } \\
\hline Yield stress (MPa) & Inelastic strain & Damage parameter & Inelastic strain \\
\hline 15.3 & $\mathbf{O}$ & o & $\mathbf{O}$ \\
\hline 19.2 & 4.8249E-05 & o & 4.8249E-05 \\
\hline 22.5 & 0.000119844 & o & 0.000119844 \\
\hline 25.2 & 0.000214786 & o & 0.000214786 \\
\hline 27.3 & 0.000333074 & o & 0.000333074 \\
\hline 28.8 & 0.000474708 & o & 0.000474708 \\
\hline 29.7 & 0.000639689 & o & 0.000639689 \\
\hline 30 & 0.000828016 & o & 0.000828016 \\
\hline 29.7 & 0.001039689 & 0.01 & 0.001039689 \\
\hline 28.8 & 0.001274708 & 0.04 & 0.001274708 \\
\hline 27.3 & 0.001533074 & 0.09 & 0.001533074 \\
\hline 25.2 & 0.001814786 & 0.16 & 0.001814786 \\
\hline 22.5 & 0.002119844 & 0.25 & 0.002119844 \\
\hline 19.2 & 0.002448249 & 0.36 & 0.002448249 \\
\hline 15.3 & 0.0028 & 0.49 & 0.0028 \\
\hline 10.8 & 0.003175097 & 0.64 & 0.003175097 \\
\hline 5.7 & 0.003573541 & 0.81 & 0.003573541 \\
\hline \multicolumn{2}{|c|}{ Concrete tensile behavior } & \multicolumn{2}{|c|}{ Concrete tension damage } \\
\hline Yield stress (MPa) & Cracking strain & $\begin{array}{c}\text { Damage parameter } \\
\mathbf{T}\end{array}$ & Cracking strain \\
\hline 3 & o & o & o \\
\hline 0.03 & 0.001167315 & 0.99 & 0.001167315 \\
\hline
\end{tabular}

Figure 4 Concrete Damaged Plasticity 


\begin{tabular}{|c|c|}
\hline JWL & TNT \\
\hline $\mathrm{Cd}(\mathrm{m} / \mathrm{s})$ & C1 (Gpa) \\
\hline 6930 & $3.73 E+11$ \\
\hline C2 (Gpa) & w \\
\hline $3.74 \mathrm{E}+09$ & 0.35 \\
\hline R1 & R2 \\
\hline 4.15 & 0.9 \\
\hline Density (kg/m^3) & $e 0\left(\mathrm{KJ} / \mathrm{m}^{\wedge} 3\right)$ \\
\hline $1.65 \mathrm{E}+03$ & $6.06 E+06$ \\
\hline
\end{tabular}

\section{Figure 5 TNT Properties For ABAQUS}

Analysis is done in dynamic explicit step type keeping the time of analysis as 0.02 second as explosion occurs in fraction of seconds(Elsaid and Seracino, 2012).

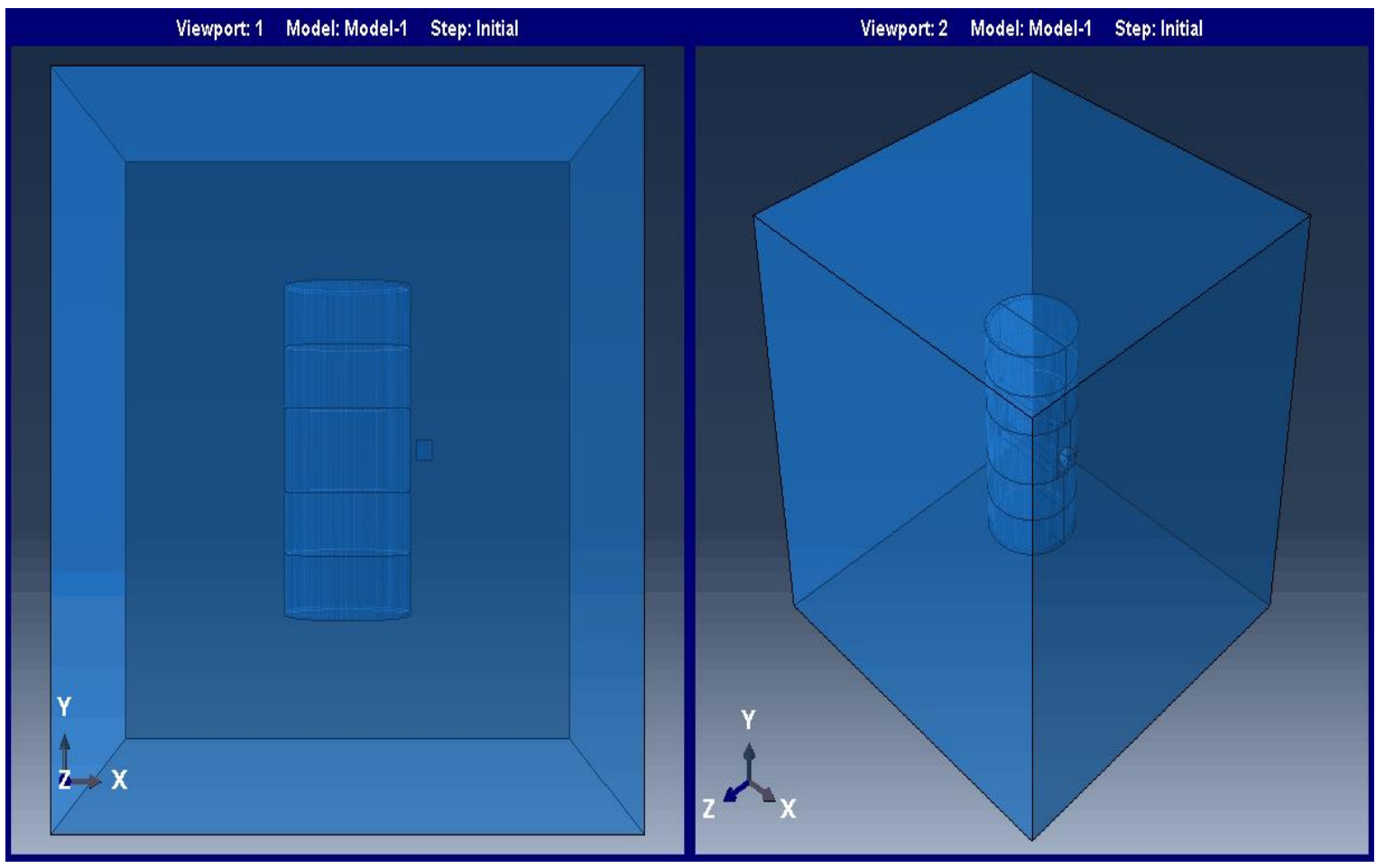

Figure 6 Eulerian Domain, TNT And Pier Assembly

In field output options we have to select few extra entities such as SDV (solution dependent stress variable), UVARM (user defined output variables), STATUS (failure in plastic model), DMIERT (damage initiative criteria), EVF (volume fraction eulerian model), etc. interaction that need to be defined in this case will be a general contact for all the surface as domain and pier is in contact and interact with each other and embedded region for reinforcement and concrete. In loading portion, we have to predefine the material water and air that we have to fill in volume fraction of the domain region(Sabuwala et al., 2005)(Ibrahim and Nabil, 2019).

\section{Result}

As the blast occurs wave takes few milliseconds of time to reach the pier surface. Explosion wave travels much faster in air than in water and does more damage in water than in air. Water provides damping effect to the pier and thus reduces the damage done due to blast. Figure 7shows the initial domain ODB view for the analysis. 


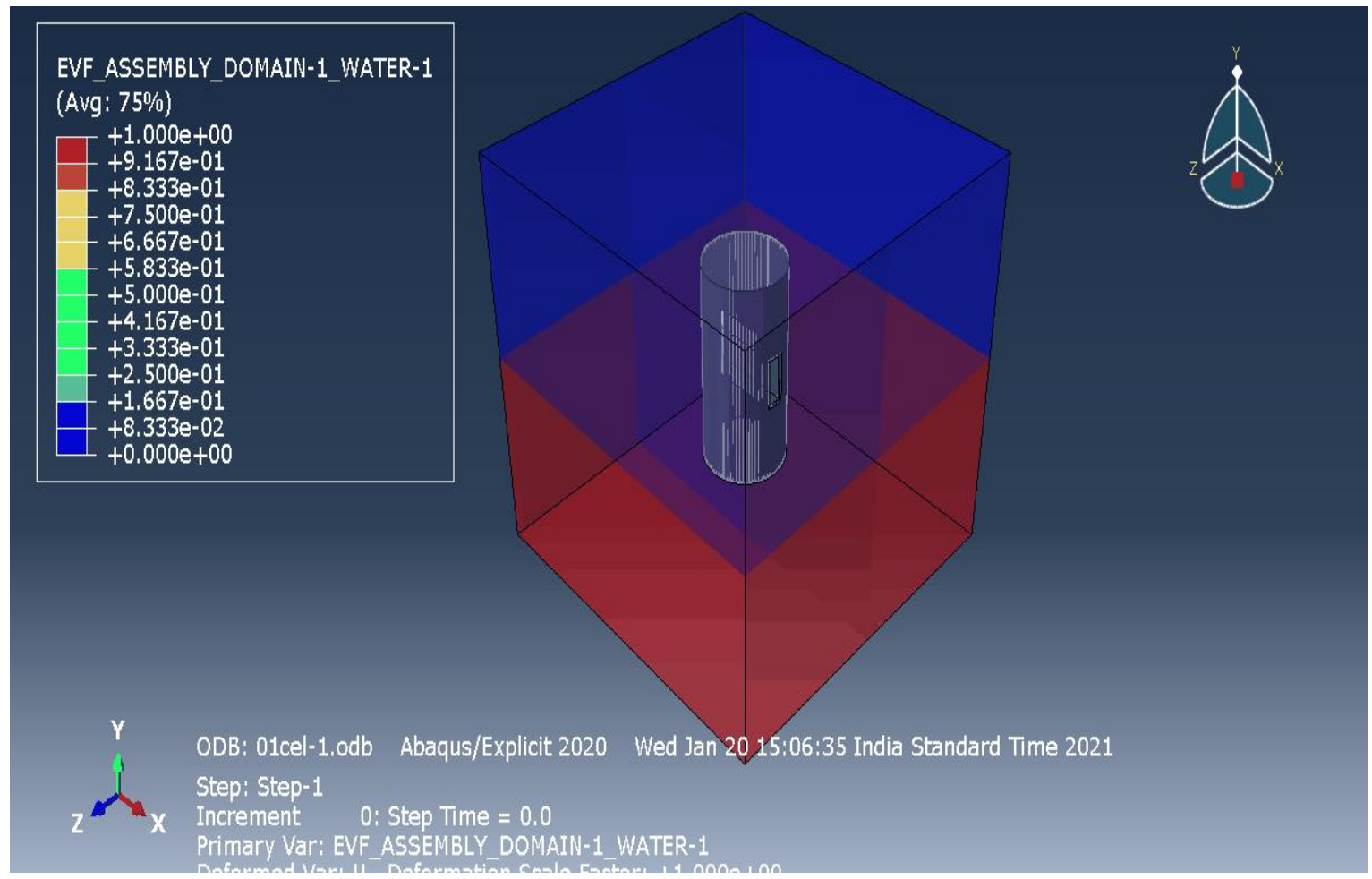

Figure 7 Initial Condition Of Domain Before Blast

Figure 8 shows the final representation of a domain after the analysis is over in 0.02 seconds. as from the figure we can say that blast wave has travelled more in air domain.

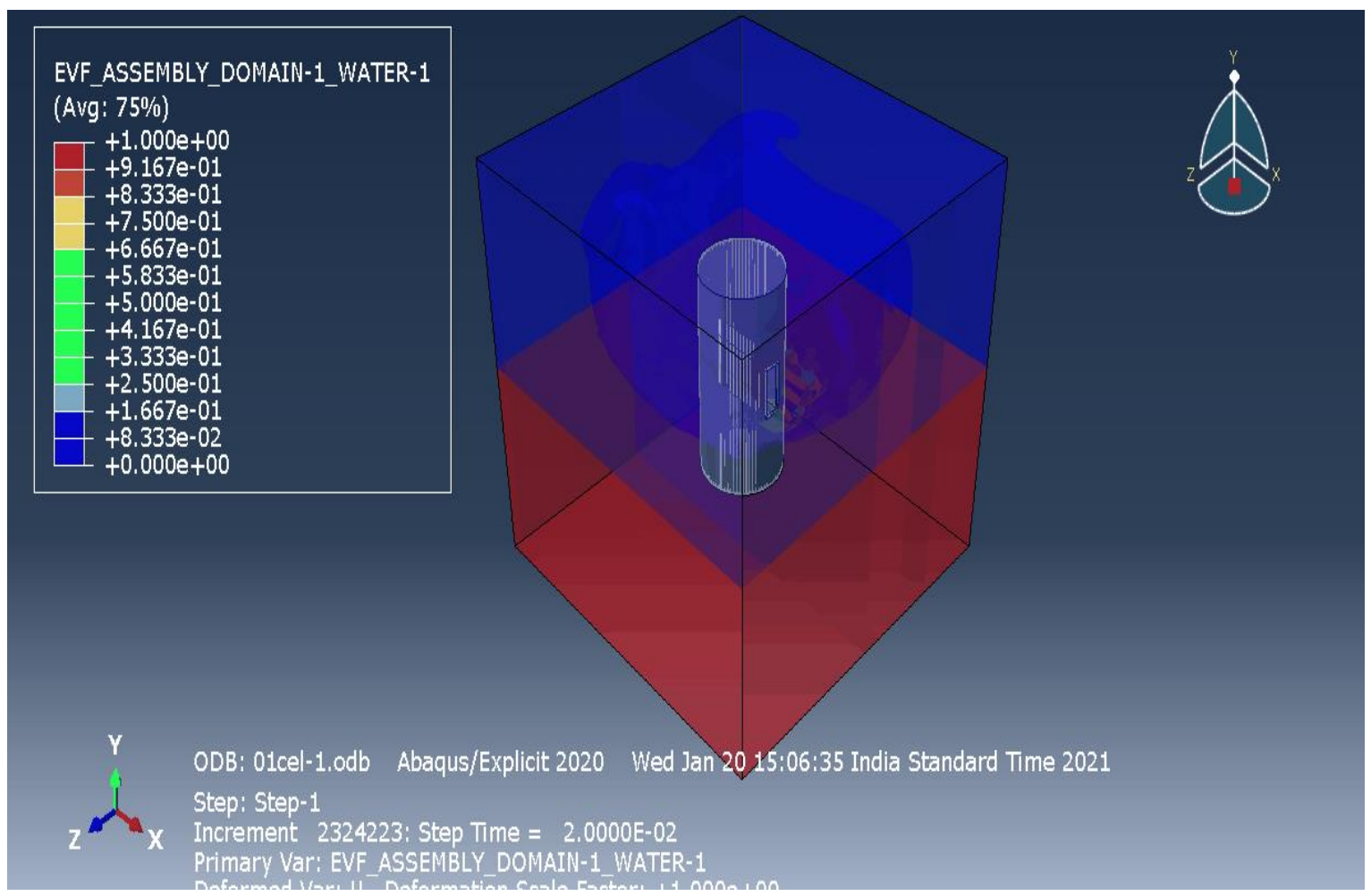

Figure 8 After Blast Representation Of Domain

As we have analyzed the pier keeping the TNT at the middle of the domain, the majority of explosion takes place in air region and damage done due to that is more in that region. 


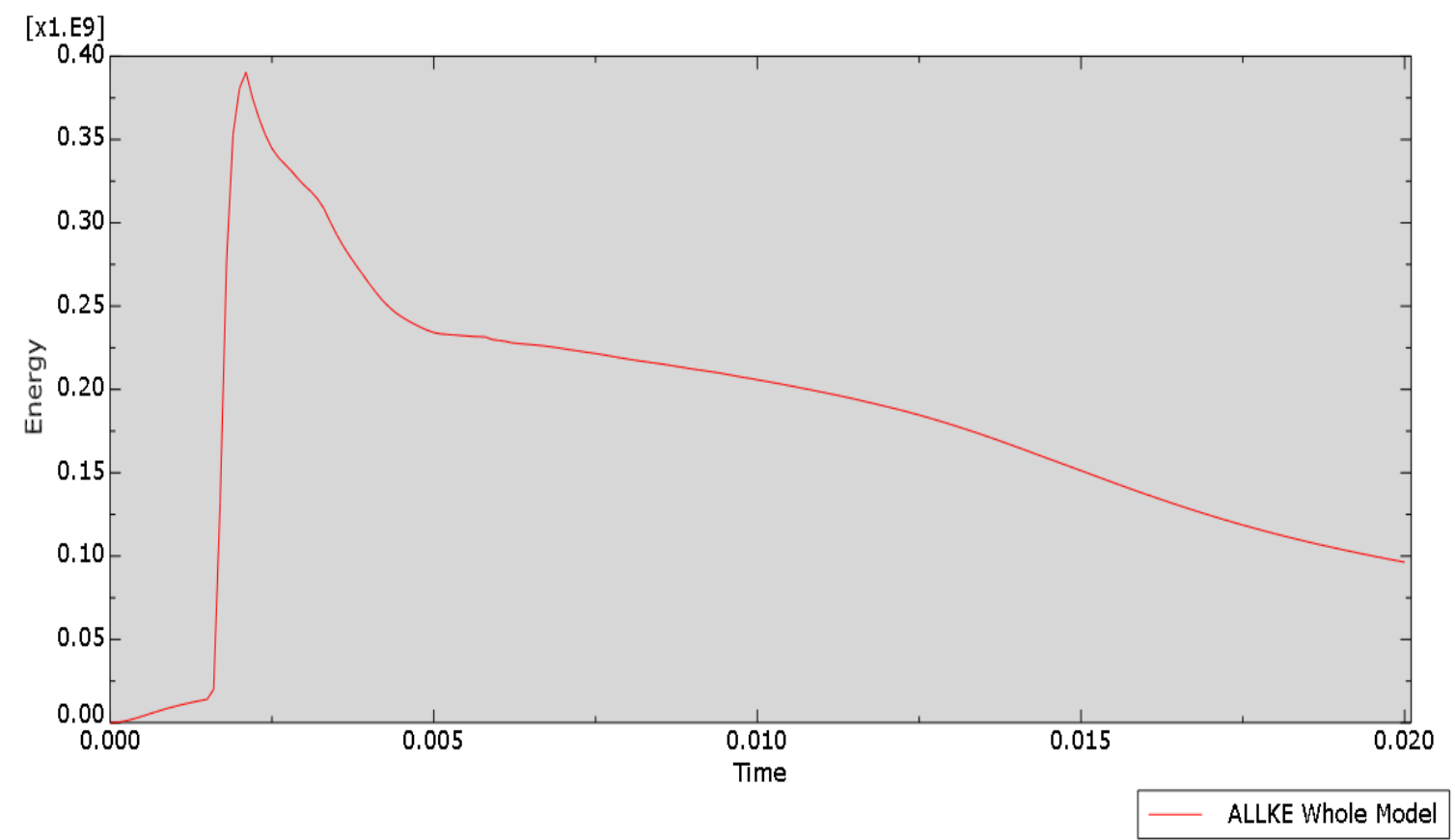

Figure 9 Kinetic Energy Of Domain W.R.T.

Figure 9shows the kinetic energy w.r.t. time. After the blast as the wave reaches the pier, sudden increase in kinetic energy is observed in the domain. From the graph we can obtain that the spike occurs at 0.0025 second which differs from the theoretical value of 0.0036 seconds by $11 \%$. After the blat the energy decays as the time passes which explains the behavior of the blast loading which is also of the type of decaying as time passes as shown in Figure 9.

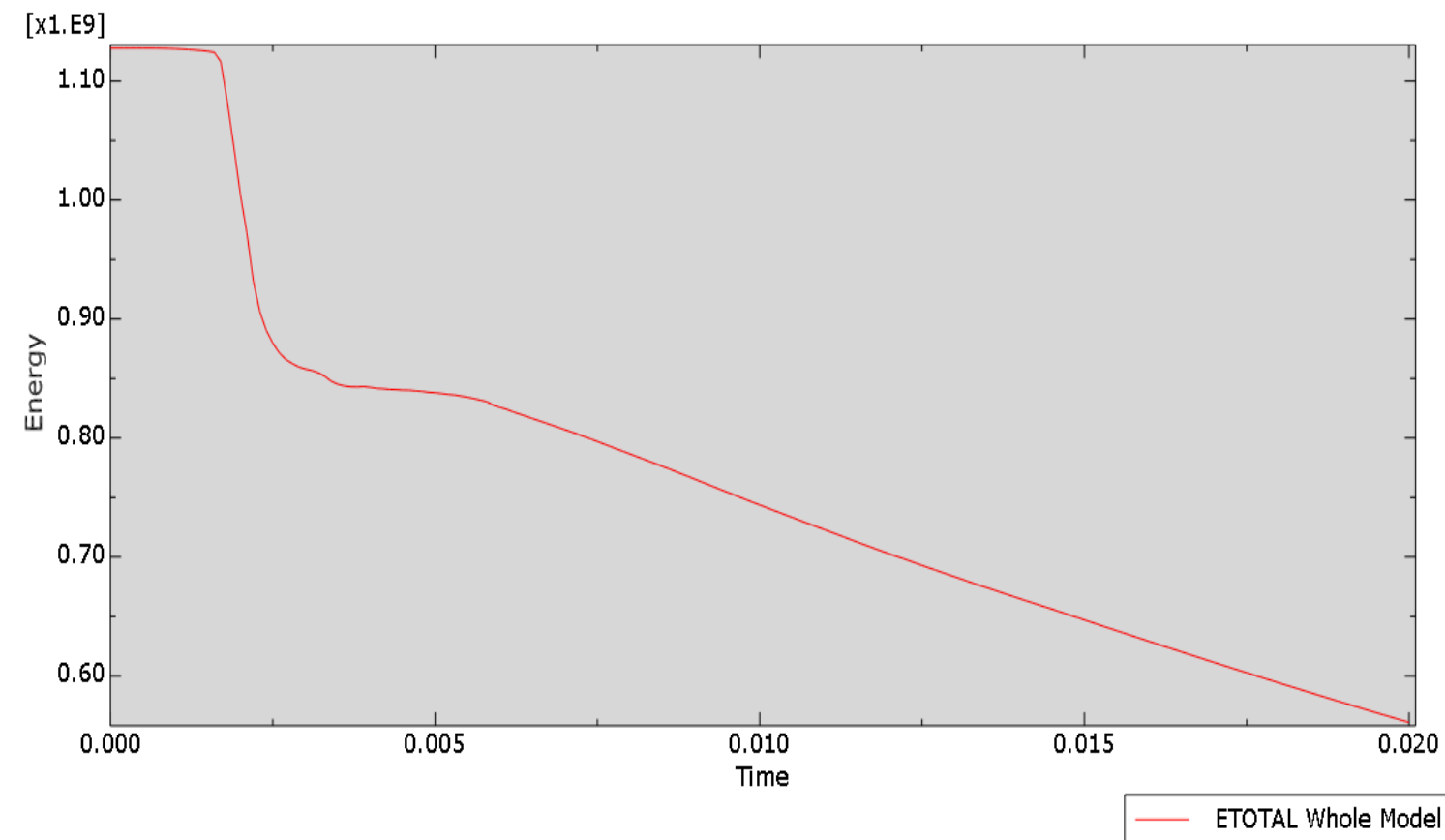

Figure 10 Total Energy Of Domain W.R.T.

Figure 10shows the total energy w.r.t. time. Total energy of the domain also decays as the blast decays as the time passes. Plateau between 0.002 to 0.003 second is observed because the sudden rise of the kinetic energy in that region. 


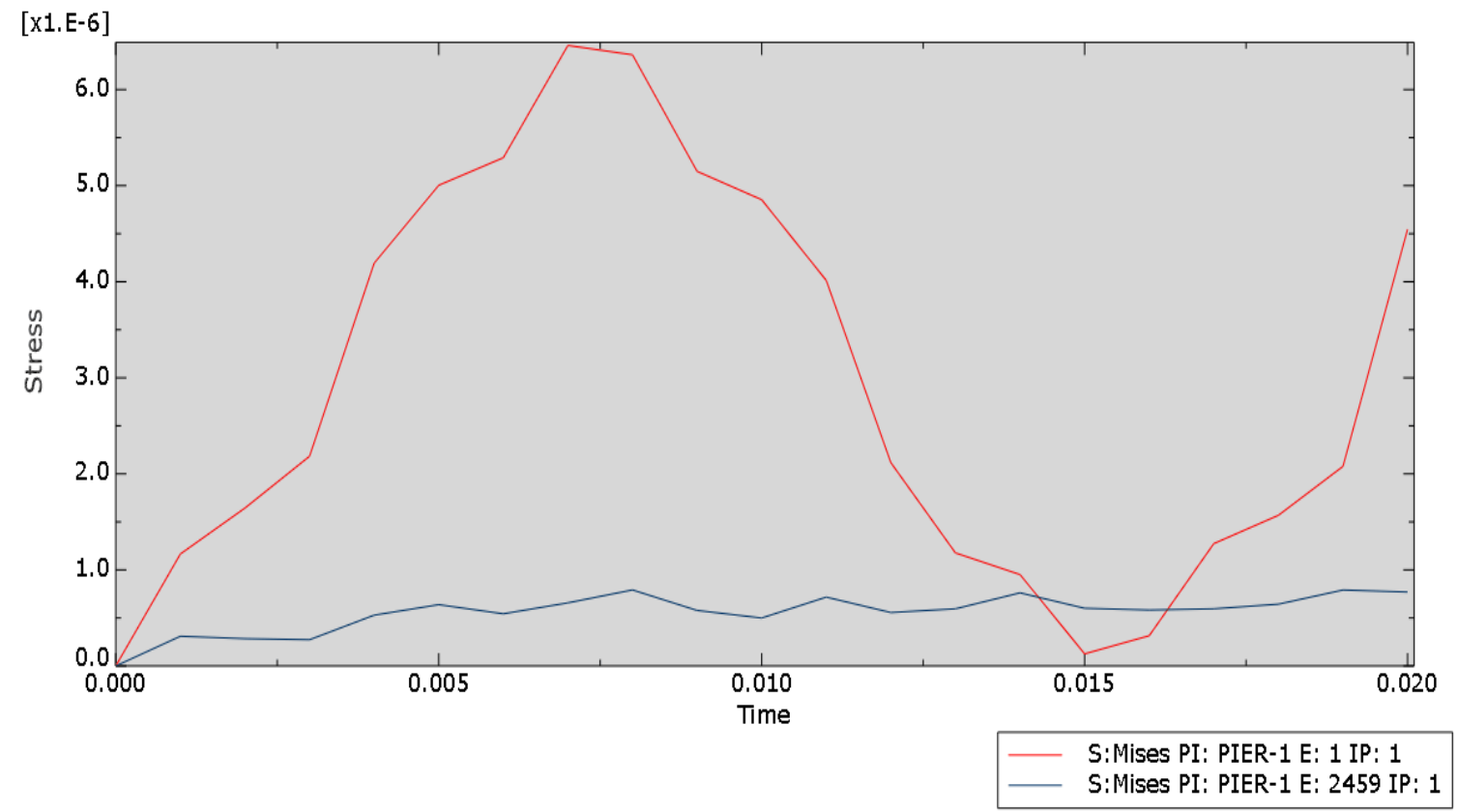

Figure 11 Stress Behavior Of Pier And Reinforcement W.R.T.

Figure 11 represents the stress behavior of pier and reinforcement w.r.t. time for a particular element of pier and reinforcement. As from the figure stresses in concrete is observed more than what is observed in reinforcement. Stresses increases as the explosion propagates in concrete and decays as blast decays. Reinforcement stresses remains almost constant as time passes.

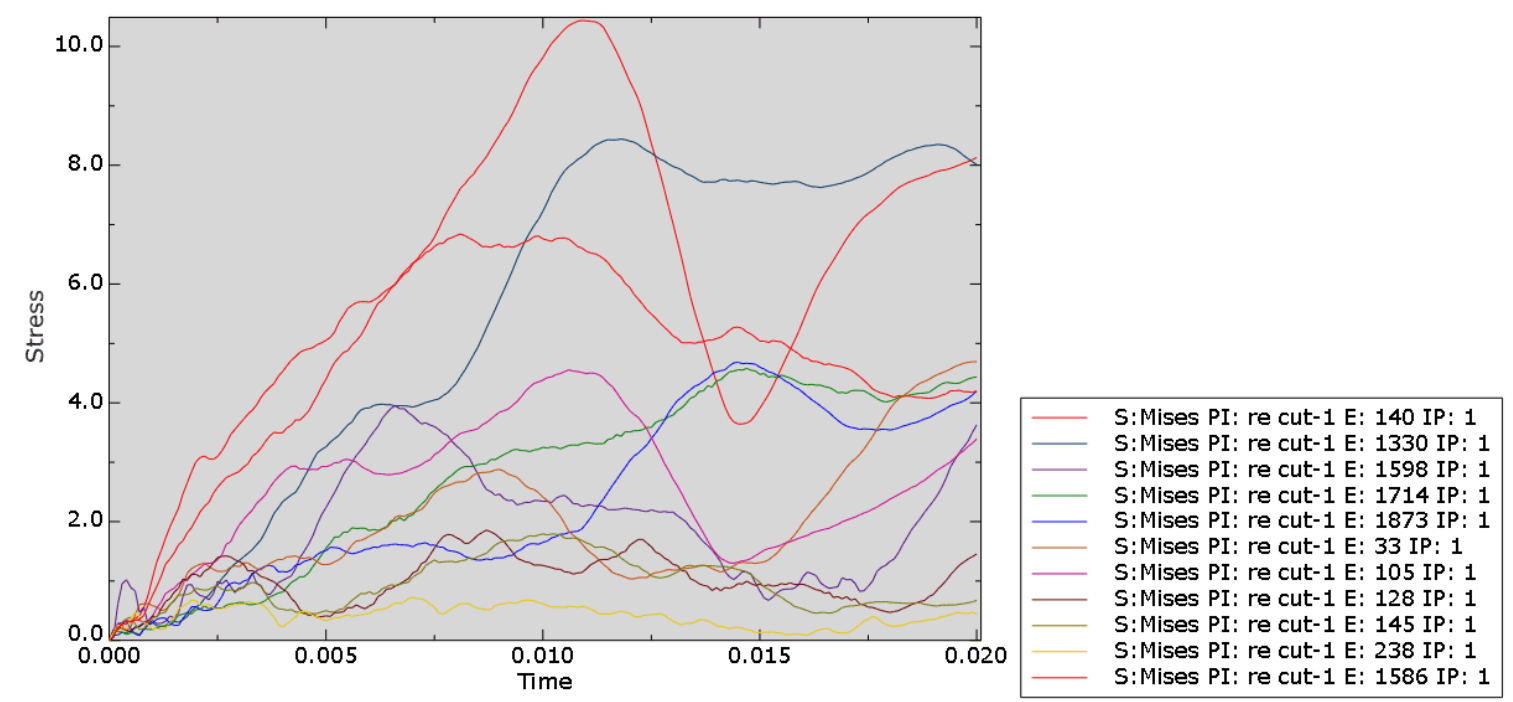

Figure 12 Stress Behavior Of Selected Reinforcement Element W.R.T.

Figure 12represents the stress variation of few selected elements of reinforcement w.r.t. time. The region facing the explosion shows the sudden spikes and higher value of stress than the region behind the blast face. Top portion of the pier does not show any variation in stress and remains almost constant with low values of stresses.

Table 2 Comparison Of Theoretical And Analytical Values

\begin{tabular}{|l|l|l|l|}
\hline ENTITY & THEORETICAL VALUE & ANALYTICAL VALUE & $\%$ ERROR \\
\hline PRESSURE & $9500 \mathrm{MPa}$ & $10000 \mathrm{MPa}$ & $5 \%$ \\
\hline IMPULSE & $350 \mathrm{MPa} \mathrm{m}-\mathrm{s}$ & $340 \mathrm{MPa} \mathrm{m}-\mathrm{s}$ & $2.85 \%$ \\
\hline
\end{tabular}




\begin{tabular}{|l|l|l|l|}
\hline TIME & $0.0036 \mathrm{~s}$ & $0.0032 \mathrm{~s}$ & $11 \%$ \\
\hline
\end{tabular}

Data in the Table 2 represents the comparison of theoretical and analytical entities required to analyze the blast.

\section{Conclusion}

Provision of slot increases the chances of scour reduction and thus increases the scour efficiency and minimize the failure due to scouring. On the same hand it reduces the strength of the pier. change in reinforcement patterns changes the behavior of the slotted pier. blast waves travel much faster in air than in water but does more damage in water than in air.

- $\quad$ Based on the results obtained from theoretical and analytical approach and as per the design suggested in NCHRP 12-72.

- As per NCHRP 12-72 structural member is design appropriately for the blast load values given in this case for the displacement and rotation that occurs in the member.

- The slotted pier is observed to reduce in strength than conventional pier under blast loading, exhibiting lower values of rotation and deformation.

- The bottom fixed part and the area near the blast, which is middle part of the pier are the area of concern. Middle portions forms a plastic hinge and fails abruptly after the blast. Bottom portion fails in shear after the blast.

The pier satisfies the criteria of design in NCHRP 12-72 and can be rehabilitated for further strength by changing the reinforcement patterns for slotted portion of the pier.

\section{References}

1. Blast-Resistant Highway Bridges: Design and Detailing Guidelines, 2010. , Blast-Resistant Highway Bridges: Design and Detailing Guidelines. https://doi.org/10.17226/22971

2. Ding, Y., Yao, Q., Zhang, Z., Wang, X., Yan, T., Yang, Y., Lv, H., 2018. A new method for scour monitoring based on fiber Bragg grating. Meas. J. Int. Meas. Confed. 127, 431-435. https://doi.org/10.1016/j.measurement.2018.03.053

3. El-Ghorab, E.A.S., 2013. Reduction of scour around bridge piers using a modified method for vortex reduction. Alexandria Eng. J. 52, 467-478. https://doi.org/10.1016/j.aej.2013.04.001

4. Elsaid, A., Seracino, R., 2012. Vibration Based Damage Detections of Scour in Coastal Bridges. Homel. Secur. Aff. 8.

5. Hafezolghorani, M., Hejazi, F., Vaghei, R., Jaafar, M.S. Bin, Karimzade, K., 2017. Simplified damage plasticity model for concrete. Struct. Eng. Int. 27, 68-78. https://doi.org/10.2749/101686616X1081

6. Heidarnejad, M., Bajestan, M.S., Masjedi, A., 2010. The Effect of Slots on Scouring Around Piers in Different Positions of 180-Degrees Bends. Appl. Sci. 8, 892-899.

7. Ibrahim, Y.E., Nabil, M., 2019. Assessment of structural response of an existing structure under blast load using finite element analysis. Alexandria Eng. J. 58, 1327-1338. https://doi.org/10.1016/j.aej.2019.11.004

8. Jin, H., Hao, H., Hao, Y., Chen, W., 2020. Predicting the response of locally resonant concrete structure under blast load. Constr. Build. Mater. 252, 118920. https://doi.org/10.1016/j.conbuildmat.2020.118920

9. Miller, P., 2004. TOWARDS THE MODELLING OF by 16, 25-48.

10. Moussa, Y.A.M., Nasr-Allah, T.H., Abd-Elhasseb, A., 2018. Studying the effect of partial blockage on multi-vents bridge pier scour experimentally and numerically. Ain Shams Eng. J. 9, 1439-1450. https://doi.org/10.1016/j.asej.2016.09.010

11. Sabuwala, T., Linzell, D., Krauthammer, T., 2005. Finite element analysis of steel beam to column connections subjected to blast loads. Int. J. Impact Eng. 31, 861-876. https://doi.org/10.1016/j.ijimpeng.2004.04.013

12. Selvakumaran, S., Plank, S., Geiß, C., Rossi, C., Middleton, C., 2018. Remote monitoring to predict bridge scour failure using Interferometric Synthetic Aperture Radar (InSAR) stacking techniques. Int. J. Appl. Earth Obs. Geoinf. 73, 463-470. https://doi.org/10.1016/j.jag.2018.07.004

13. Syed, Z.I., Mohamed, O.A., Rahman, S.A., 2016. Non-linear Finite Element Analysis of Offshore Stainless Steel Blast Wall under High Impulsive Pressure Loads. Procedia Eng. 145, 1275-1282. https://doi.org/10.1016/j.proeng.2016.04.164

14. Wu, P., Balachandar, R., Ramamurthy, A., 2018. Effects of splitter plate on reducing local scour around bridge pier. River Res. Appl. 34, 1338-1346. https://doi.org/10.1002/rra.3363

15. Zhang, C., Gholipour, G., Mousavi, A.A., 2020. Blast loads induced responses of RC structural members: State-of-the-art review. Compos. Part $\quad$ B 
https://doi.org/10.1016/j.compositesb.2020.108066

16. Zhang, W., Uh Zapata, M., Bai, X., Pham-Van-Bang, D., Nguyen, K.D., 2020. Three-dimensional simulation of horseshoe vortex and local scour around a vertical cylinder using an unstructured finitevolume technique. Int. J. Sediment Res. 35, 295-306. https://doi.org/10.1016/j.ijsrc.2019.09.001 